\title{
Association of polymorphisms in LEPR with type 2 diabetes and related metabolic traits in a Chinese population
}

Lulu Zhang ${ }^{1,2+}$, Yingfen Qin ${ }^{3 \dagger}$, Danyan Liang ${ }^{4}$, Li Li ${ }^{3}$, Yaojie Liang ${ }^{5}$, Lulin Chen ${ }^{1,2}$, Lei Tong ${ }^{1,2}$, Jia Zhou ${ }^{3}$, Hong Li ${ }^{6^{*}}$ and Haiying Zhang ${ }^{1,2,7^{*}}$

\begin{abstract}
Background: Leptin acts as a mediator of inflammation and energy homeostasis by activating leptin receptor $(L E P R)$. We conducted this study to explore the association of polymorphisms in LEPR with type 2 diabetes mellitus (T2DM) and its related metabolic traits.

Methods: We performed a case-control study to investigate the association of polymorphisms in LEPR with T2DM and related metabolic traits in a Chinese population, with a total of 922 T2DM patients and 1031 nondiabetic subjects. Polymorphisms were genotyped using MassARRAY assay.

Results: The $G$ allele of rs 1327118 was associated with a decreased risk of T2DM in men ( $P=0.044$, odds ratio $=0.707$, $95 \%$ confidence interval $=0.504-0.991$ ) and the $\mathrm{G}$ allele of $\mathrm{rs} 3806318$ was associated with increased systolic blood pressure (SBP) in men with T2DM. Besides, the women patients carrying the G allele of rs 1327118 showed increased SBP and diastolic blood pressure (DBP) levels, but decreased high density lipoprotein cholesterol (HDL-C) level.

Conclusion: Our results suggest that rs 1327118 may be associated with SBP, DBP and HDL-C levels in women with T2DM, and rs3806318 may be associated with T2DM and SBP level in men with T2DM. Further studies with larger sample size or functional experiments focused on exact mechanism are required to verify our observations.
\end{abstract}

Keywords: Type 2 diabetes mellitus, LEPR gene, Polymorphism, Blood pressure

\section{Background}

Diabetes has become a serious public health concern around the world. In 2015, more than 415 million people suffered from diabetes and three quarters of diabetic patients lived in low and middle income countries. At present, China has about 109 million patients with diabetes, and the number of patients is expected to increase to 151 million by 2040, of which type 2 diabetes mellitus (T2DM) accounts for about 95\% [1]. T2DM has become one of the major causes of death [2].

T2DM is a multifactorial complex disease that results from the interaction of genetic variants with environmental

\footnotetext{
* Correspondence: hnlihong@gxmu.edu.cn; zhanghaiying@gxmu.edu.cn ${ }^{\dagger}$ Equal contributors

${ }^{6}$ School of General Medicine, Guangxi Medical University, Nanning 530021, People's Republic of China

${ }^{1}$ School of Public Health, Guangxi Medical University, Nanning 530021,

People's Republic of China

Full list of author information is available at the end of the article
}

factors [3, 4], and is characterized by chronic elevated blood glucose levels. A large number of studies [5-10] have shown that genetic factors are considered to be the main cause of individual differences in T2DM and the occurrence of T2DM has obvious genetic heterogeneity. All these studies indicate that genetic variation is an important cause of individual differences in susceptibility to T2DM. There are many genes that interact with environment leading to T2DM. According to the genome-wide association analysis, nearly 60 loci are reported to be associated with T2DM [11, 12]. However, the exact pathogenesis of T2DM is still unclear.

Leptin, first discovered by the group led by Jeffrey Friedman in 1994 [13], is mainly secreted by adipose tissue and is a forerunner of adipokines. Once secreted into the circulation, leptin reaches the central and peripheral nervous systems and then acts by activating leptin receptor $(L E P R)$ in the hypothalamus to alter the 
expression of several neuropeptides, which can regulate food intake and appetite, basal metabolism, reproductive function, bone mass and insulin secretion [14, 15]. LEPR is located in chromosome $1 \mathrm{p} 31$, and contains 20 exons spanning about $100 \mathrm{~kb}$ [16]. LEPR can regulate lipid metabolism, blood pressure and blood glucose [16]. The absence of $L E P R$ leads to increased food appetite and body fat mass [17]. Additionally, $L E P R$ is present in pancreatic $\beta$-cells and may be involved in the onset of chronic hyperglycemia and uncontrolled T2DM [18]. Polymorphisms in LEPR gene have been investigated in many association studies of obesity, T2DM and diabetes-related complications in recent years [19-23]. These findings suggest that $L E P R$ polymorphisms may be associated with the onset and development of obesity and T2DM. Two LEPR polymorphisms, rs3806318 and rs1327118, are both located in near gene $5^{\prime}$ of $L E P R$. Several studies have demonstrated that the two polymorphisms in $L E P R$ may participate in the progression of cancer and inflammatory response [24-27]. Notably, certain cancer [28-30] and inflammatory response [31-35] may be involved in the pathogenesis of T2DM. And so far limited studies have explored the association between the two polymorphisms and T2DM in different ethnics. Taking this into account, we conducted this study to investigate the association of the selected polymorphisms of LEPR with type 2 diabetes in a Chinese population.

\section{Methods}

\section{Study subjects}

We performed a case-control study including 929 unrelated T2DM patients and 1044 nondiabetic healthy subjects from 2010 to 2015 in the First Affiliated Hospital of Guangxi Medical University. All the subjects ( $\geq 40$ years) who underwent routine physical examination were enrolled. All the participants were requested to undertake a standard $2 \mathrm{~h}$ of oral glucose $(75 \mathrm{~g})$ tolerance test. T2DM patients were diagnosed according to WHO criteria(a fasting glucose level of $\geq 7.0 \mathrm{mmol} / \mathrm{Land} / \mathrm{or}$ a $2 \mathrm{~h}$ glucose level of $\geq 11.1 \mathrm{mmol} / \mathrm{L}$, and/or a self-reported history of T2DM). Those with type 1 diabetes, cancer, or any kind of severe metabolic diseases were excluded. Healthy individuals with normal blood glucose level and glucose tolerance (fasting glucose level of $<6.1 \mathrm{mmol} / \mathrm{L}$ and $2 \mathrm{~h}$ glucose level of $<7.8 \mathrm{mmol} / \mathrm{L}$ ), and no family history of T2DM were recruited as controls. A standard questionnaire was used to assess the socio-demographic information, family history of T2DM and so on. All procedures performed in this study involving human participants were approved by the Ethics Committee of Guangxi Medical University (Nanning, P. R. China). Informed consent was obtained from all subjects.

\section{Measurements}

Anthropometric measurements were conducted by trained medical staff according to standard approaches. Body weight and height were accurately measured to the nearest $0.1 \mathrm{~kg}$ and $0.1 \mathrm{~cm}$ in light clothing without shoes. Body mass index (BMI) was calculated as weight in kilograms divided by squared height in meters $(\mathrm{kg} / \mathrm{m} 2)$. Blood pressures were measured three times on the right arm using an automated blood pressure monitor (Omron, Kyoto, Japan) in a seated position after an at least 5-min rest, and the mean blood pressure was calculated for further analysis. Biochemical indicators including fasting plasma glucose (FPG), total cholesterol (TC), triglyceride (TG), high density lipoprotein cholesterol (HDL-C), low density lipoprotein cholesterol (LDL-C), hemoglobin A1c (HbA1c), were assessed using a B200 Auto Analyzer.

\section{Genotyping}

Blood samples were drawn with minimal trauma from participants' antecubital vein in the morning after an overnight fast and stored at $-80{ }^{\circ} \mathrm{C}$ before analysis. DNA was extracted from peripheral blood leukocytes using the QIAamp DNA blood kit (Tiangen Biotech Co., Ltd., Beijing, China) according to the manufacturer's instructions. The quality of the extracted DNA was evaluated by electrophoresis on $0.8 \%$ agarose gel and the quantity was evaluated by nanodrop device of A260 nm/A280 $\mathrm{nm}$. The MassARRAY Assay Design 3.0 software (Sequenom) was used to design the detection primers and the MassARRAY genotyping system (Sequenom) was used to genotype polymorphisms. Two polymorphisms, rs3806318 and rs1327118 were selected from the International HapMap Project. The genotyping detection rate of the two polymorphisms was up to $95 \%$ or over, and finally 922 T2DM patients and 1031 controls were genotyped successfully.

\section{Statistical analysis}

Clinical and laboratory data were compared between groups by unpaired Student's independent $t$ test or chisquare test. Continuous variables with normal distributions are described as mean \pm standard deviation and categorical variables were presented as percentage (\%). Chi-squared test was used to compare the allele and genotype frequencies between T2DM group and control group and to test deviations from Hardy-Weinberg equilibrium. We conducted a logistic regression analysis to evaluate the association of investigated polymorphisms with T2DM by odds ratio (ORs) and 95\% confidence interval (CI). General and biochemical characteristics were compared between different genotypes using a general linear model (GLM) analysis adjusted for covariates. A level of $P$-value $<0.05$ was considered as statistically significant, and all statistical tests were 
Table 1 Demographic and biochemical characteristics of the study subjects

\begin{tabular}{llll}
\hline & T2DM $(n=922)$ & Non-diabetic $(n=1031)$ & $P$-value \\
\hline Male $(\mathrm{n} \%)^{\mathrm{a}}$ & $361(39.2)$ & $390(37.8)$ & 0.576 \\
${\text { Age }(\text { years })^{\mathrm{b}}}$ & $64.9 \pm 10.1$ & $64.0 \pm 9.5$ & 0.065 \\
$\mathrm{BMI}\left(\mathrm{kg} / \mathrm{m}^{2}\right)^{\mathrm{b}}$ & $25.1 \pm 3.6$ & $24.0 \pm 3.2$ & $\mathbf{0 . 0 0 0}$ \\
$\mathrm{SBP}(\mathrm{mmHg})^{\mathrm{b}}$ & $139.3 \pm 20.6$ & $133.7 \pm 19.4$ & $\mathbf{0 . 0 0 0}$ \\
$\mathrm{DBP}(\mathrm{mmHg})^{\mathrm{b}}$ & $81.0 \pm 11.7$ & $78.9 \pm 11.0$ & $\mathbf{0 . 0 0 0}$ \\
$\mathrm{FPG}(\mathrm{mmol} / \mathrm{L})^{\mathrm{b}}$ & $7.7 \pm 2.6$ & $5.5 \pm 0.5$ & $\mathbf{0 . 0 0 0}$ \\
$\mathrm{HbA} 1 \mathrm{C}(\%)^{\mathrm{b}}$ & $6.8 \pm 1.6$ & $5.6 \pm 0.5$ & $\mathbf{0 . 0 0 0}$ \\
$\mathrm{HDL}-\mathrm{C}(\mathrm{mmol} / \mathrm{L})^{\mathrm{b}}$ & $1.2 \pm 0.4$ & $1.3 \pm 0.4$ & $\mathbf{0 . 0 0 0}$ \\
$\mathrm{LDL}-\mathrm{C}(\mathrm{mmol} / \mathrm{L})^{\mathrm{b}}$ & $3.1 \pm 1.0$ & $3.0 \pm 0.9$ & 0.133 \\
$\mathrm{TG}(\mathrm{mmol} / \mathrm{L})^{\mathrm{b}}$ & $2.0 \pm 1.7$ & $1.4 \pm 1.0$ & $\mathbf{0 . 0 0 0}$ \\
$\mathrm{TC}(\mathrm{mmol} / \mathrm{L})^{\mathrm{b}}$ & $5.3 \pm 1.5$ & $5.1 \pm 1.3$ & $\mathbf{0 . 0 0 2}$
\end{tabular}

T2DM type 2 diabetes mellitus, $B M I$ body mass index, SBP systolic blood pressure, DBP diastolic blood pressure, FPG fasting plasma glucose, $\mathrm{HbA1c}$ Hemoglobin A1c, HDL-C HDL cholesterol, LDL-C LDL cholesterol, TG triglyceride, TC total cholesterol

${ }^{a} P$-values were obtained by chi-square tests

${ }^{\mathrm{b}} P$-values were obtained by student's independent $\mathrm{t}$-test

$P$ values in boldface are significant

two-tailed. Statistical analysis were performed using SPSS Version 17.0 (SPSS Inc., Chicago, IL, USA).

\section{Results}

\section{Basic characteristics of the study subjects}

The basic characteristics of T2DM patients and control subjects are shown in Table 1. The significant differences were found in BMI, systolic blood pressure (SBP), diastolic blood pressure (DBP), FPG, HbA1C, HDL-C, TC and TG between the two groups $(P<0.05)$, and there was no significant difference between the two groups in age, gender and LDL-C level $(P>0.05)$.

\section{Genotype and allele distributions}

The overall genotypic and allelic frequencies of rs3806318 and rs1327118 in T2DM patients and nondiabetic subjects are shown in Table 2. The genotype and allele distribution of rs3806318 and rs1327118 all conformed to HardyWeinberg equilibrium $(P>0.05)$. No significant difference in the genotype and allele frequencies of both polymorphisms was observed between the two groups $(P>0.05)$.

The distribution of allele and genotype frequencies of both polymorphisms between male T2DM patients and controls are shown in Table 3. Male individuals carrying G allele of rs1327118 showed a decreased risk of developing T2DM compared with $\mathrm{C}$ allele carriers $(P=0.044)$, whereas the CG and GG genotypes did not confer a risk to T2DM. However, no significant difference in the frequencies of both polymorphisms was observed between the two groups in females (Table 4).

\section{Association between polymorphisms in LEPR and diabetes-related metabolic traits}

Table 5 shows the demographic and clinical characteristics of T2DM patients according to the presence of the minor alleles of $L E P R$ polymorphisms. When the entire population was divided into male and female groups, the $G$ allele of rs3806318 was associated with increased SBP level in men with T2DM after adjustment for age and BMI $(P=0.033)$, but no significant associations were observed in women between rs3806318 and metabolic traits. Women with T2DM carrying the $G$ allele of rs1327118 showed increased SBP and DBP levels, but decreased HDL-C level compared with $\mathrm{C} / \mathrm{C}$ carriers after adjustment for age and BMI $(P=0.004, P=0.026$ and $P$ $=0.033$, respectively), but there was no significant

Table 2 Distributions of alleles and genotypes between T2DM patients and control subjects

\begin{tabular}{|c|c|c|c|c|}
\hline Polymorphism & T2DM & Non-diabetic & Unadjusted $P^{a}$ & Adjusted OR(95\% Cl)/P \\
\hline rs3806318 & $n=925$ & $n=1038$ & & \\
\hline $\mathrm{AA}$ & $741(80.1 \%)$ & $827(79.7 \%)$ & 0.964 & 1 \\
\hline$A G$ & 173(18.7\%) & 199(19.2\%) & & $1.038(0.650-1.660) / 0.875$ \\
\hline GG & $11(1.2 \%)$ & $12(1.1 \%)$ & & $0.971(0.638-1.476) / 0.889$ \\
\hline A & 1655(89.5\%) & $1162(89.3 \%)$ & 0.839 & 1 \\
\hline G & 195(10.5\%) & $128(10.7 \%)$ & & $0.999(0.811-1.231) / 0.995$ \\
\hline rs1327118 & $n=922$ & $n=1031$ & & \\
\hline $\mathrm{CC}$ & 726(79.7\%) & 798(77.4\%) & 0.721 & 1 \\
\hline$C G$ & $178(19.2 \%)$ & $214(20.8 \%)$ & & $1.063(0.712-1.588) / 0.764$ \\
\hline GG & $18(1.1 \%)$ & $19(1.8 \%)$ & & $1.011(0.716-1.427) / 0.952$ \\
\hline C & 1630(88.4\%) & 1810(87.8\%) & 0.562 & 1 \\
\hline G & $214(11.6 \%)$ & $252(12.2 \%)$ & & $1.055(0.866-1.286) / 0.593$ \\
\hline
\end{tabular}

T2DM type 2 diabetes mellitus

${ }^{\text {a }} P$-values were obtained by chi-square tests

${ }^{\mathrm{b}} P$-values were obtained by logistic regression analysis adjusted for age, gender, BMI

$P$ values in boldface are significant 
Table 3 Distributions of alleles and genotypes between T2DM patients and control subjects in males

\begin{tabular}{|c|c|c|c|c|}
\hline Polymorphism & T2DM & Non-diabetic & Unadjusted $P^{a}$ & Adjusted OR(95\% CI)/Pb \\
\hline rs3806318 & $n=363$ & $n=393$ & & \\
\hline AA & 287(79.1\%) & $302(76.9 \%)$ & 0.756 & 1 \\
\hline$A G$ & $73(20.1 \%)$ & $87(22.1 \%)$ & & $1.020(0.439-2.370) / 0.964$ \\
\hline GG & $3(0.8 \%)$ & $4(1.0 \%)$ & & $0.880(0.404-1.915) / 0.747$ \\
\hline A & 647(89.1\%) & $691(87.9 \%)$ & 0.463 & 1 \\
\hline G & $79(10.9 \%)$ & $95(12.1 \%)$ & & $0.894(0.639-1.251) / 0.514$ \\
\hline rs1327118 & $n=361$ & $n=390$ & & \\
\hline $\mathrm{CC}$ & 293(81.2\%) & $300(76.9 \%)$ & 0.252 & 1 \\
\hline CG & $65(18.0 \%)$ & $83(21.3 \%)$ & & $1.491(0.628-3.541) / 0.365$ \\
\hline GG & $3(0.8 \%)$ & $7(1.8 \%)$ & & $0.512(0.230-1.136) / 0.100$ \\
\hline C & $651(90.2 \%)$ & 683(87.6\%) & 0.110 & 1 \\
\hline G & $71(9.8 \%)$ & $97(12.4 \%)$ & & $0.707(0.504-0.991) / 0.044$ \\
\hline
\end{tabular}

T2DM type 2 diabetes mellitus

${ }^{\text {a }} P$-values were obtained by chi-square tests

${ }^{\mathrm{b}} P$-values were obtained by logistic regression analysis adjusted for age, BMI

$P$ values in boldface are significant

difference in metabolic traits among male patients with different genotypes.

\section{Discussion}

In this study, we investigated the association of $L E P R$ polymorphisms rs3806318 and rs1327118 with T2DM and T2DM-related quantitative traits in a Chinese population. The association of the two polymorphisms in LEPR with T2DM susceptibility wasn't observed in the total subjects, while G allele of rs1327118 might decrease the risk of T2DM adjusted for covariates in men. As to metabolic traits, women with T2DM carrying the $G$ allele of rs1327118 showed increased SBP and DBP levels, but decreased HDL-cholesterol level compared with $\mathrm{C} / \mathrm{C}$ carriers after adjustment for age and BMI. Moreover, the G allele of rs3806318 was associated with increased SBP in men with T2DM adjusted for age and BMI.

Leptin, as an adipocyte-derived protein, plays an important role in the regulation of appetite and food intake, bone mass, basal metabolism and insulin secretion via $L E P R$ $[14,15]$. In addition, leptin can stimulate inflammatory response and promote the growth of some cancer cells [3638]. Numerous studies have suggested that T2DM is a chronic inflammatory disease, and inflammatory response plays an important role in the onset and development of T2DM [31-35]. Meanwhile, certain cancers share many risk factors with T2DM, and are closely linked to the development of T2DM [28-30]. All these studies suggest

Table 4 Distributions of alleles and genotypes between T2DM patients and control subjects in females

\begin{tabular}{|c|c|c|c|c|}
\hline Polymorphism & T2DM & Non-diabetic & Unadjusted $P^{a}$ & Adjusted OR(95\% Cl)/Pb \\
\hline rs3806318 & $n=363$ & $n=393$ & & \\
\hline $\mathrm{AA}$ & $287(79.1 \%)$ & $302(76.9 \%)$ & 0.941 & 1 \\
\hline$A G$ & $73(20.1 \%)$ & $87(22.1 \%)$ & & $0.990(0.558-1.7561) / 0.972$ \\
\hline GG & $3(0.8 \%)$ & $4(1.0 \%)$ & & $1.062(0.643-1.753) / 0.816$ \\
\hline A & 647(89.1\%) & $691(87.9 \%)$ & 0.746 & 1 \\
\hline G & 79(10.9\%) & $95(12.1 \%)$ & & $1.053(0.805-1.378) / 0.704$ \\
\hline rs1327118 & $n=361$ & $n=390$ & & \\
\hline CC & $293(81.2 \%)$ & $300(76.9 \%)$ & 0.644 & 1 \\
\hline$C G$ & $65(18.0 \%)$ & $83(21.3 \%)$ & & $0.849(0.522-1.381) / 0.509$ \\
\hline GG & $3(0.8 \%)$ & $7(1.8 \%)$ & & $1.240(0.824-1.868) / 0.303$ \\
\hline C & $651(90.2 \%)$ & $683(87.6 \%)$ & 0.627 & 1 \\
\hline G & $71(9.8 \%)$ & $97(12.4 \%)$ & & $1.112(0.868-1.425) / 0.402$ \\
\hline
\end{tabular}

T2DM type 2 diabetes mellitus

${ }^{\text {a }} P$-values were obtained by chi-square tests

${ }^{\mathrm{b}} P$-values were obtained by logistic regression analysis adjusted for age, BMI

$P$ values in boldface are significant 
Table 5 Demographic and biochemical features of T2DM patients according to the minor alleles of LEPR rs3806318 and rs1327118 polymorphisms

\begin{tabular}{|c|c|c|c|c|c|c|c|c|}
\hline \multirow[t]{2}{*}{ Polymorphisms } & \multicolumn{3}{|c|}{ Wild-type homozygous } & \multicolumn{3}{|c|}{ Heterozygous + Mutated homozygous } & \multirow{2}{*}{$\begin{array}{l}\text { Unadjusted } P \mathrm{~m} / f_{;} \\
\text {adjusted } P \mathrm{~m} / \mathrm{f}^{*}\end{array}$} & \multirow{2}{*}{$\begin{array}{l}\text { Unadjusted } \\
P_{;} \text {adjusted } \\
P^{\Delta}\end{array}$} \\
\hline & Male & Female & Total & Male & Female & Total & & \\
\hline rs1327118 & \multicolumn{3}{|l|}{$C C(n=726)$} & \multicolumn{3}{|c|}{$\mathrm{CG}+\mathrm{GG}(n=196)$} & & \\
\hline $\operatorname{Sex}(\%)$ & 293(40.3) & 433(59.6) & 726 & $68(34.7)$ & $128(65.3)$ & 196 & - & $0.161 ;-$ \\
\hline Age(years) & $63.8 \pm 10.1$ & $65.5 \pm 10.0$ & $64.8 \pm 10.1$ & $64.9 \pm 10.6$ & $65.1 \pm 9.7$ & $65.0 \pm 9.9$ & 0.442/0.719;- & $0.781 ;-$ \\
\hline $\mathrm{BMI}\left(\mathrm{kg} / \mathrm{m}^{2}\right)^{\mathrm{a}}$ & $25.3 \pm 3.7$ & $25.2 \pm 3.7$ & $25.2 \pm 3.7$ & $25.0 \pm 3.0$ & $24.6 \pm 3.3$ & $24.8 \pm 3.2$ & $0.526 / 0.113 ; 0.557 / 0.107$ & $0.091 ; 0.099$ \\
\hline $\mathrm{SBP}(\mathrm{mmHg})^{\mathrm{b}}$ & $138.8 \pm 20.4$ & $138.4 \pm 19.6$ & $138.6 \pm 19.9$ & $139.6 \pm 20.0$ & $143.5 \pm 20.0$ & $142.2 \pm 22.8$ & 0.787/0.014;0.794/0.004 & $0.030 ; 0.010$ \\
\hline $\mathrm{DBP}(\mathrm{mmHg})^{\mathrm{b}}$ & $82.9 \pm 12.0$ & $79.4 \pm 10.6$ & $80.8 \pm 11.3$ & $81.6 \pm 13.2$ & $81.8 \pm 12.5$ & $81.7 \pm 12.7$ & $0.441 / 0.032 ; 0.500 / \mathbf{0 . 0 2 6}$ & $0.327 ; 0.181$ \\
\hline $\mathrm{FPG}(\mathrm{mmol} / \mathrm{L})^{\mathrm{b}}$ & $7.8 \pm 2.6$ & $7.6 \pm 2.6$ & $7.6 \pm 2.6$ & $8.1 \pm 2.6$ & $7.6 \pm 2.4$ & $7.7 \pm 2.5$ & $0.399 / 0.934 ; 0.384 / 0.879$ & $0.613 ; 0.555$ \\
\hline $\mathrm{HbA} 1 \mathrm{c}(\%)^{\mathrm{b}}$ & $6.7 \pm 1.6$ & $6.8 \pm 1.6$ & $6.7 \pm 1.6$ & $7.0 \pm 1.6$ & $6.8 \pm 1.6$ & $6.8 \pm 1.6$ & $0.230 / 0.845 ; 0.264 / 0.966$ & $0.570 ; 0.536$ \\
\hline $\mathrm{HDL}-\mathrm{C}(\mathrm{mmol} / \mathrm{L})^{\mathrm{b}}$ & $1.1 \pm 0.3$ & $1.33 \pm 0.4$ & $1.3 \pm 0.4$ & $1.1 \pm 0.3$ & $1.26 \pm 0.3$ & $1.2 \pm 0.3$ & 0.692/0.056;0.397/0.033 & $0.141 ; 0.024$ \\
\hline $\mathrm{LDL}-\mathrm{C}(\mathrm{mmol} / \mathrm{L})^{\mathrm{b}}$ & $2.9 \pm 1.0$ & $3.2 \pm 1.0$ & $3.1 \pm 1.0$ & $3.0 \pm 1.1$ & $3.2 \pm 1.0$ & $3.1 \pm 1.1$ & $0.586 / 0.916 ; 0.973 / 0.886$ & $0.685 ; 0.862$ \\
\hline $\mathrm{TG}(\mathrm{mmol} / \mathrm{L})^{\mathrm{b}}$ & $2.0 \pm 1.8$ & $2.0 \pm 1.6$ & $2.0 \pm 1.7$ & $2.1 \pm 1.1$ & $1.9 \pm 1.4$ & $2.0 \pm 1.7$ & $0.640 / 0.472 ; 0.498 / 0.543$ & $0.819 ; 0.908$ \\
\hline $\mathrm{TC}(\mathrm{mmol} / \mathrm{L})^{\mathrm{b}}$ & $4.9 \pm 1.3$ & $5.6 \pm 1.5$ & $5.3 \pm 1.5$ & $5.0 \pm 1.4$ & $5.4 \pm 1.5$ & $5.3 \pm 1.5$ & $0.468 / 0.422 ; 0.804 / 0.313$ & $0.971 ; 0.431$ \\
\hline rs3806318 & \multicolumn{3}{|l|}{$\mathrm{AA}(n=741)$} & \multicolumn{3}{|c|}{$\mathrm{GA}+\mathrm{GG}(n=184)$} & & \\
\hline $\operatorname{Sex}(\%)$ & 287(38.7) & $454(61.3)$ & 741 & $76(41.3)$ & 108(58.7) & 184 & - & $0.555 ;^{-}$ \\
\hline Age(years) & $63.8 \pm 10.1$ & $65.5 \pm 10.1$ & $64.9 \pm 10.1$ & $64.6 \pm 10.4$ & $65.0 \pm 9.5$ & $64.8 \pm 9.8$ & 0.568/0.531;- & $0.957 ;-$ \\
\hline $\mathrm{BMI}\left(\mathrm{kg} / \mathrm{m}^{2}\right)^{\mathrm{a}}$ & $25.4 \pm 3.6$ & $25.1 \pm 3.6$ & $25.2 \pm 3.6$ & $24.8 \pm 3.5$ & $24.8 \pm 3.5$ & $24.8 \pm 3.5$ & 0.188/0.419;0.197/0.399 & $0.147 ; 0.139$ \\
\hline $\mathrm{SBP}(\mathrm{mmHg})^{\mathrm{b}}$ & $138.3 \pm 20.3$ & $139.4 \pm 21.0$ & $139.0 \pm 20.7$ & $141.3 \pm 20.3$ & $140.2 \pm 19.7$ & $140.6 \pm 19.9$ & $0.255 / 0.731 ; 0.177 / 0.583$ & $0.330 ; 0.214$ \\
\hline $\mathrm{DBP}(\mathrm{mmHg})^{\mathrm{b}}$ & $82.1 \pm 12.3$ & $79.8 \pm 11.4$ & $80.7 \pm 11.8$ & $84.9 \pm 11.8$ & $80.4 \pm 10.1$ & $82.2 \pm 11.0$ & $0.075 / 0.659 ; \mathbf{0 . 0 3 3} / 0.580$ & $0.116 ; 0.076$ \\
\hline $\mathrm{FPG}(\mathrm{mmol} / \mathrm{L})^{\mathrm{b}}$ & $7.9 \pm 2.7$ & $7.6 \pm 2.6$ & $7.7 \pm 2.6$ & $7.6 \pm 2.5$ & $7.4 \pm 2.4$ & $7.5 \pm 2.5$ & $0.390 / 0.562 ; 0.423 / 0.548$ & $0.336 ; 0.310$ \\
\hline $\mathrm{HbA1c}(\%)^{b}$ & $6.8 \pm 1.6$ & $6.8 \pm 1.6$ & $6.8 \pm 1.6$ & $6.6 \pm 1.5$ & $6.8 \pm 1.5$ & $6.7 \pm 1.5$ & $0.313 / 0.818 ; 0.285 / 0.781$ & $0.647 ; 0.669$ \\
\hline $\mathrm{HDL}-\mathrm{C}(\mathrm{mmol} / \mathrm{L})^{\mathrm{b}}$ & $1.1 \pm 0.3$ & $1.3 \pm 0.4$ & $1.2 \pm 0.4$ & $1.2 \pm 0.4$ & $1.3 \pm 0.4$ & $1.3 \pm 0.4$ & $0.103 / 0.409 ; 0.151 / 0.493$ & $0.148 ; 0.153$ \\
\hline $\mathrm{LDL}-\mathrm{C}(\mathrm{mmol} / \mathrm{L})^{\mathrm{b}}$ & $2.9 \pm 1.1$ & $3.2 \pm 1.0$ & $3.1 \pm 1.1$ & $3.0 \pm 0.9$ & $3.3 \pm 1.0$ & $3.2 \pm 1.0$ & 0.432/0.213;0.413/0.178 & $0.175 ; 0.116$ \\
\hline $\mathrm{TG}(\mathrm{mmol} / \mathrm{L})^{\mathrm{b}}$ & $2.0 \pm 1.9$ & $1.9 \pm 1.5$ & $2.0 \pm 1.7$ & $1.9 \pm 1.5$ & $2.1 \pm 1.5$ & $2.0 \pm 1.5$ & $0.598 / 0.351 ; 0.680 / 0.353$ & $0.773 ; 0.807$ \\
\hline $\mathrm{TC}(\mathrm{mmol} / \mathrm{L})^{\mathrm{b}}$ & $4.9 \pm 1.3$ & $5.5 \pm 1.5$ & $5.2 \pm 1.5$ & $5.0 \pm 1.3$ & $5.7 \pm 1.5$ & $5.4 \pm 1.4$ & $0.368 / 0.117 ; 0.396 / 0.067$ & $0.107 ; 0.053$ \\
\hline
\end{tabular}

$B M I$ body mass index, SBP systolic blood pressure, $D B P$ diastolic blood pressure, FPG fasting plasma glucose, $H b A 1 c$ Hemoglobin $A 1 c, H D L-C$ HDL cholesterol, $L D L-C$ LDL cholesterol, TG triglyceride, $T C$ total cholesterol

M, male; f, female; Unadjusted $P$ values was obtained by chi-square test or student's test; Adjusted $P$ values was obtained by general linear model analysis after adjusting for covariates. However, the gender covariate was not included in after stratification by gender

adjusted for age and gender

badjusted for age, gender and BMI

*Results after stratification by gender

${ }^{\Delta}$ Results for the total sample

$P$ values in boldface are significant

that leptin and $L E P R$ may be involved in the pathogenesis of T2DM. Polymorphisms in LEPR are reported to participate in the onset of T2DM [20, 22, 23], and rs3806318 and rs1327118 in $L E P R$ are also identified to contribute to cancer $[24,25,27]$ and inflammatory response [26]. However, to the best of our knowledge, no study has investigated the association of LEPR polymorphisms rs3806318 and rs1327118 with T2DM and related metabolic traits in Chinese population. In our study, the $G$ allele of rs1327118 may decrease the risk of T2DM in men, whereas the CG and GG genotypes did not confer a risk to T2DM. The reason why the association wasn't observed in genotype distribution may be due to the relatively insufficient male sample.
As mentioned above, $L E P R$ can participate in glucose and lipid metabolism. In our study, there was no association between the two polymorphisms of $L E P R$ and lipid levels in addition to HDL level. However, both polymorphisms showed a significant association with blood pressure. These results indicated that polymorphisms of rs3806318 and rs1327118 may influence blood pressure in T2DM patients. It has been reported that increasing levels of leptin in dietinduced obesity (DIO) mice drives an increase in blood pressure and re-expression of $L E P R$ in DIO LEPR-deficient mice also lead to an increase in blood pressure, while humans with loss-of-function mutations in leptin and $L E P R$ have low blood pressure [39]. Shannon et al. [40] suggest that the $L E P R^{L 985}(l / l)$ mice have higher arterial pressure 
compared with wild-type controls and a significant association has been previously observed between polymorphisms in LEPR and blood pressure [41]. Han et al. [42] also demonstrate that certain polymorphisms of leptin are associated with T2DM and SBP. Leptin's effects on blood pressure are regulated by neuronal circuits in the dorsomedial hypothalamus [39] and leptin can increase sympathetic nerve activity, and eventually contribute to elevated blood pressure $[43,44]$. Furthermore, there is evidence that hypertension and T2DM often coexist and are more likely to contribute to cardiovascular disease [45]. The precise mechanism of these associations remains unclear. Hence further researches are necessary to clarify these associations.

Our study reported significant gender-specific associations of polymorphisms in LEPR with T2DM and its related metabolic traits. Sex-specific differences have been previously demonstrated in the onset and development of T2DM and related metabolic diseases [46, 47], and sexspecific genetic background may lead to the different effect of genetic variation on body composition [48]. Gender difference for polymorphisms in leptin and $L E P R$, as well as some other genes have been reported in some association studies of T2DM. Brondani et al. [49] indicate that FNDC5 variant is associated with changes in blood pressure and lipid profile only in women with T2DM. Ogawa et al. [50] suggest that the serum soluble leptin receptor level in men is significantly higher than that in women. On the contrary, Saad et al. reveal that women have a significant higher leptin level than men at the similar age and body fat [51]. Babic et al. [52] report that plasma leptin is associated with pancreatic cancer risk only in men and leptin levels are higher in women, and rs10493380 in $L E P R$ is associated with increased pancreatic cancer risk only in women. There are also many experimental animal models to demonstrate sex differences in metabolism and diseases. It is reported that ablation of $L E P R$ causes severe growth hormone deficiency and abdominal obesity in male mice [53]. Nuno et al. [54] discover sex-dependent differences of vascular contractile dysfunction in type 2 diabetic mice. Sex differences in qualitative changes and quantitative changes of metabolic diseases in SDT fatty rats are also observed by Ohta et al. [55]. Taken together, our study also suggest that gender-differences exist in polymorphisms of $L E P R$ in a Chinese population.

Our study has some limitations. Firstly, we didn't measure LEPR expression levels which may demonstrate these gender-specific associations. Secondly, behaviors of smoking and alcohol consumption were not evaluated in this study, which may have an influence on the incidence of T2DM. Nevertheless, our study firstly investigated the association of rs3806318 and rs1327118 in LEPR with T2DM and metabolic traits in a Chinese population. Further studies with larger male samples are required to verify these gender-specific results.

\section{Conclusions}

Our results suggest that the polymorphism rs1327118 may be associated with SBP, DBP and HDL-C levels in women with T2DM, and the G allele of rs3806318 may be associated with higher SBP in men T2DM patients. Further studies with larger male samples are required to verify our gender-specific results.

\begin{abstract}
Abbreviations
BMI: Body mass index; DBP: Diastolic blood pressure; DIO: Diet-induced obesity; FPG: Fasting plasma glucose; HbA1c: Hemoglobin A1c; HDL-C: High density lipoprotein cholesterol; LDL-C: High density lipoprotein cholesterol; LEPR: Leptin receptor; SBP: Systolic blood pressure; T2DM: Type 2 diabetes mellitus; TC: Total cholesterol; TG: Triglyceride
\end{abstract}

\section{Acknowledgments}

We are grateful to all the staff members in the Department of endocrinology of the First Affiliated Hospital of Guangxi Medical University and Beijing Genomics Institute.

\section{Funding}

This study was supported by the National Natural Science Foundation of China (Nos. 81460159, 81760145 and 81260130) and Provincial Natural Science Foundation of Guangxi (Nos.2017GXNSFDA198032) and Important Specific Projects for "Precision Medicine" 2016 National Annual Project (Nos.2016YFC0901200 and 2016YFC0901205) and Scientific Research Specific Projects for Public Welfare (Medical) (No.201502007).

\section{Availability of data and materials}

The datasets used and analysed during the current study are available from the corresponding author on reasonable request.

\section{Authors' contributions}

$L Z$ and $Y Q$ drafted the paper. DL and $L L$ analyzed the data. YL, LC, LT and JZ performed the experiments. $\mathrm{HL}$ revised the manuscript and $\mathrm{HZ}$ conceived and designed the study. All authors have read and approved the final manuscript.

\section{Ethics approval and consent to participate}

All procedures performed in this study involving human participants were approved by the Ethics Committee of Guangxi Medical University (Nanning, P. R. China). Informed consent was obtained from all subjects.

Consent for publication

Not applicable.

Competing interests

The authors declare that they have no competing interests.

\section{Publisher's Note}

Springer Nature remains neutral with regard to jurisdictional claims in published maps and institutional affiliations.

\section{Author details}

${ }^{1}$ School of Public Health, Guangxi Medical University, Nanning 530021, People's Republic of China. ${ }^{2}$ Guangxi Colleges and Universities Key Laboratory of Prevention and Control of Highly Prevalent Diseases, Guangxi Medical University, Nanning 530021, People's Republic of China. ${ }^{3}$ Department of Endocrine, First Affiliated Hospital of Guangxi Medical University, Nanning 530021, People's Republic of China. ${ }^{4}$ Third Affiliated Hospital of Guangxi Medical University, Nanning 530021, People's Republic of China. ${ }^{5}$ Beihai Center for Disease Prevention and Control, Beihai 536000, People's Republic of China. ${ }^{6}$ School of General Medicine, Guangxi Medical University, Nanning 530021, People's Republic of China. ${ }^{7}$ Guangxi key laboratory for genomic and personalized medicine, Guangxi collaborative innovation center for genomic and personalized medicine, Guangxi Medical University, Nanning 530021, People's Republic of China. 
Received: 31 October 2017 Accepted: 13 December 2017

\section{Published online: 04 January 2018}

\section{References}

1. International Diabetes Federation. IDF Diabetes Atlas, 7. http://www.diabetesatlas. org; 2015.

2. GBD 2015 Mortality and Causes of Death Collaborators. Global, regional, and national life expectancy, all-cause mortality, and cause-specific mortality for 249 causes of death, 1980-2015: a systematic analysis for the global burden of disease study 2015. Lancet (London, England). 2016;388:1459-544.

3. Sladek R, Rocheleau G, Rung J, Dina C, Shen L, Serre D, et al. A genomewide association study identifies novel risk loci for type 2 diabetes. Nature. 2007:445:881-5.

4. Qin J, Li Y, Cai Z, Li S, Zhu J, Zhang F, et al. A metagenome-wide association study of gut microbiota in type 2 diabetes. Nature. 2012;490:55-60.

5. Ma RC, Hu C, Tam CH, Zhang R, Kwan P, Leung TF, et al. Genome-wide association study in a Chinese population identifies a susceptibility locus for type 2 diabetes at 7q32 near PAX4. Diabetologia. 2013;56:1291-305.

6. Moltke I, Grarup N, Jorgensen ME, Bjerregaard P, Treebak JT, Fumagalli M, et al. A common Greenlandic TBC1D4 variant confers muscle insulin resistance and type 2 diabetes. Nature. 2014;512:190-3.

7. Tang ST, Shen XR, Tang HQ, Wang CJ, Wei W, Zhang Q, et al. Association of the ENPP1 K121Q polymorphism with susceptibility to type 2 diabetes in different populations: evidence based on 40 studies. Endocr J. 2014;61:1093-103.

8. Flannick J, Thorleifsson G, Beer NL, Jacobs SB, Grarup N, Burtt NP, et al. Lossof-function mutations in SLC30A8 protect against type 2 diabetes. Nat Genet. 2014;46:357-63

9. Dong Y, Guo T, Traurig M, Mason CC, Kobes S, Perez J, et al. SIRT1 is associated with a decrease in acute insulin secretion and a sex specific increase in risk for type 2 diabetes in pima Indians. Mol Genet Metab. 2011;104:661-5.

10. Lee JK, Kim K, Ahn Y, Yang M, Lee JE. Habitual coffee intake, genetic polymorphisms, and type 2 diabetes. Eur J Endocrinol. 2015;172:595-601.

11. Scott RA, Lagou V, Welch RP, Wheeler E, Montasser ME, Luan J, et al. Largescale association analyses identify new loci influencing glycemic traits and provide insight into the underlying biological pathways. Nat Genet. 2012;44: 991-1005.

12. Morris AP, Voight BF, Teslovich TM, Ferreira T, Segre AV, Steinthorsdottir $V$, et al. Large-scale association analysis provides insights into the genetic architecture and pathophysiology of type 2 diabetes. Nat Genet. 2012:44:981-90.

13. Zhang Y, Proenca R, Maffei M, Barone M, Leopold L, Friedman JM. Positional cloning of the mouse obese gene and its human homologue. Nature. 1994; 372:425-32.

14. Mantzoros CS. The role of leptin in human obesity and disease: a review of current evidence. Ann Intern Med. 1999;130:671-80.

15. Abella V, Scotece M, Conde J, Pino J, Gonzalez-Gay MA, Gomez-Reino JJ, et al. Leptin in the interplay of inflammation, metabolism and immune system disorders. Nat Rev Rheumatol. 2017;13:100-9.

16. Zhang F, Chen Y, Heiman M, Dimarchi R. Leptin: structure, function and biology. Vitam Horm. 2005;71:345-72.

17. Scarpace PJ, Zhang Y. Elevated leptin: consequence or cause of obesity? Frontiers in bioscience : a journal and virtual library. 2007;12:3531-44.

18. Denroche HC, Huynh FK, Kieffer TJ. The role of leptin in glucose homeostasis. Journal of diabetes investigation. 2012;3:115-29.

19. Sahin S, Rustemoglu A, Tekcan A, Tasliyurt T, Guven H, Yigit S. Investigation of associations between obesity and LEP G2548A and LEPR 668A/G polymorphisms in a Turkish population. Dis Markers. 2013;35:673-7.

20. Liao WL, Chen CC, Chang CT, Wu JY, Chen CH, Huang YC, et al. Gene polymorphisms of adiponectin and leptin receptor are associated with early onset of type 2 diabetes mellitus in the Taiwanese population. International journal of obesity (2005). 2012;36:790-6.

21. Mohammadzadeh G, Nikzamir A, Mohammadi J, Pourdashti S, Shabazian H, Latifi SM. Association of the 223A/G LEPR polymorphism with serum leptin levels in Iranian subjects with type 2 diabetes. Archives of Iranian medicine. 2013:16:636-41.

22. Yang MM, Wang J, Fan JJ, Ng TK, Sun DJ, Guo X, et al. Variations in the obesity gene "LEPR" contribute to risk of type 2 diabetes mellitus: evidence from a meta-analysis. Journal of diabetes research. 2016;2016:5412084.

23. Su S, Zhang C, Zhang F, Li H, Yang $X$, Tang $X$. The association between leptin receptor gene polymorphisms and type 2 diabetes mellitus: a systematic review and meta-analysis. Diabetes Res Clin Pract. 2016;121: 49-58.
24. Chen X, Xiang Y-B, Long J-R, Cai H, Cai Q, Cheng J, et al. Genetic polymorphisms in obesity-related genes and endometrial cancer risk. Cancer. 2012;118:3356-64.

25. Teras LR, Goodman M, Patel AV, Bouzyk M, Tang W, Diver WR, et al. No association between polymorphisms in LEP, LEPR, ADIPOQ, ADIPOR1, or ADIPOR2 and postmenopausal breast cancer risk. Cancer epidemiology, biomarkers \& prevention : a publication of the American Association for Cancer Research, cosponsored by the American Society of Preventive Oncology. 2009;18:2553-7.

26. Zhang YY, Gottardo L, Mlynarski W, Frazier W, Nolan D, Duffy J, et al. Genetic variability at the leptin receptor (LEPR) locus is a determinant of plasma fibrinogen and C-reactive protein levels. Atherosclerosis. 2007;191:121-7.

27. Zhang Y, Wang MY, He J, Wang JC, Yang YJ, Jin L, et al. Tumor necrosis factoralpha induced protein 8 polymorphism and risk of non-Hodgkin's lymphoma in a Chinese population: a case-control study. PLoS One. 2012;7:e37846.

28. Gallagher EJ, LeRoith D. Obesity and diabetes: the increased risk of cancer and cancer-related mortality. Physiol Rev. 2015;95:727-48.

29. Shlomai G, Neel B, LeRoith D, Gallagher EJ. Type 2 diabetes mellitus and cancer: the role of pharmacotherapy. Journal of clinical oncology : official journal of the American Society of Clinical Oncology. 2016;34:4261-9.

30. Volkers N. Diabetes and cancer: scientists search for a possible link. J Natl Cancer Inst. 2000:92:192-4.

31. Pickup JC, Mattock MB, Chusney GD, Burt D. NIDDM as a disease of the innate immune system: association of acute-phase reactants and interleukin-6 with metabolic syndrome X. Diabetologia. 1997;40:1286-92.

32. Spranger J, Kroke A, Mohlig M, Hoffmann K, Bergmann MM, Ristow M, et al. Inflammatory cytokines and the risk to develop type 2 diabetes: results of the prospective population-based European prospective investigation into cancer and nutrition (EPIC)-Potsdam study. Diabetes. 2003;52:812-7.

33. Herder C, Illig T, Rathmann W, Martin S, Haastert B, Muller-Scholze S, et al. Inflammation and type 2 diabetes: results from KORA Augsburg. Gesundheitswesen (Bundesverband der Arzte des Offentlichen Gesundheitsdienstes (Germany)). 2005;67(Suppl 1):S115-21.

34. Herder C, Brunner EJ, Rathmann W, Strassburger K, Tabak AG, Schloot NC, et al. Elevated levels of the anti-inflammatory interleukin-1 receptor antagonist precede the onset of type 2 diabetes: the Whitehall II study. Diabetes Care. 2009:32:421-3.

35. Pradhan AD, Manson JE, Rifai N, Buring JE, Ridker PM. C-reactive protein, interleukin 6, and risk of developing type 2 diabetes mellitus. JAMA. 2001;286:327-34.

36. Lam QL, Lu L. Role of leptin in immunity. Cellular \& molecular immunology. 2007:4:1-13.

37. Burgos-Ramos E, Sackmann-Sala L, Baquedano E, Cruz-Topete D, Barrios V, Argente $J$, et al. Central leptin and insulin administration modulates serum cytokine- and lipoprotein-related markers. Metab Clin Exp. 2012;61:1646-57.

38. Tilg H, Moschen AR. Adipocytokines: mediators linking adipose tissue, inflammation and immunity. Nat Rev Immunol. 2006;6:772-83.

39. Simonds SE, Pryor JT, Ravussin E, Greenway FL, Dileone R, Allen AM, et al. Leptin mediates the increase in blood pressure associated with obesity. Cell. 2014;159: 1404-16.

40. Harlan SM, Morgan DA, Dellsperger DJ, Myers MG Jr, Mark AL, Rahmouni K. Cardiovascular and sympathetic effects of disrupting tyrosine 985 of the leptin receptor. Hypertension. 2011;57:627-32.

41. Rosmond R, Chagnon YC, Holm G, Chagnon M, Perusse L, Lindell K, et al. Hypertension in obesity and the leptin receptor gene locus. J Clin Endocrinol Metab. 2000;85:3126-31.

42. Han HR, Ryu HJ, Cha HS, Go MJ, Ahn Y, Koo BK, et al. Genetic variations in the leptin and leptin receptor genes are associated with type 2 diabetes mellitus and metabolic traits in the Korean female population. Clin Genet. 2008;74:105-15.

43. Haynes W. Interaction between leptin and sympathetic nervous system in hypertension. Curr Hypertens Rep. 2000;2:311-8.

44. Haynes W, Morgan D, Djalali A, Sivitz W, Mark A. Interactions between the melanocortin system and leptin in control of sympathetic nerve traffic. Hypertension. 1999;33:542-7.

45. Ferrannini E, Cushman WC. Diabetes and hypertension: the bad companions. Lancet (London, England). 2012;380:601-10.

46. Onat A, Hergenc G, Keles I, Dogan Y, Turkmen S, Sansoy V. Sex difference in development of diabetes and cardiovascular disease on the way from obesity and metabolic syndrome. Metab Clin Exp. 2005;54:800-8.

47. Duan JG, Chen XY, Wang L, Lau A, Wong A, Thomas GN, et al. Sex differences in epidemiology and risk factors of acute coronary syndrome in Chinese patients with type 2 diabetes: a long-term prospective cohort study. PLoS One. 2015;10:e0122031. 
48. Zillikens MC, Yazdanpanah M, Pardo LM, Rivadeneira F, Aulchenko YS, Oostra BA, et al. Sex-specific genetic effects influence variation in body composition. Diabetologia. 2008;51:2233-41.

49. Brondani LA, Boelter G, Assmann TS, Leitao CB, Canani LH, Crispim D. Irisinencoding gene (FNDC5) variant is associated with changes in blood pressure and lipid profile in type 2 diabetic women but not in men. Metab Clin Exp. 2015;64:952-7.

50. Ogawa T, Hirose H, Yamamoto Y, Nishikai K, Miyashita K, Nakamura H, et al. Relationships between serum soluble leptin receptor level and serum leptin and adiponectin levels, insulin resistance index, lipid profile, and leptin receptor gene polymorphisms in the Japanese population. Metab Clin Exp. 2004:53:879-85.

51. Saad MF, Damani S, Gingerich RL, Riad-Gabriel MG, Khan A, Boyadjian R, et al. Sexual dimorphism in plasma leptin concentration. J Clin Endocrinol Metab. 1997:82:579-84

52. Babic A, Bao Y, Qian ZR, Yuan C, Giovannucci EL, Aschard H, et al. Pancreatic cancer risk associated with Prediagnostic plasma levels of Leptin and Leptin receptor genetic polymorphisms. Cancer Res. 2016;76:7160-7.

53. Allensworth-James ML, Odle A, Haney A, Childs G. Sex differences in Somatotrope dependency on Leptin receptors in young mice: ablation of LEPR causes severe growth hormone deficiency and abdominal obesity in males. Endocrinology. 2015;156:3253-64.

54. Nuno DW, Harrod JS, Lamping KG. Sex-dependent differences in rho activation contribute to contractile dysfunction in type 2 diabetic mice. Am J Physiol Heart Circ Physiol. 2009;297:H1469-77.

55. Ohta T, Katsuda Y, Miyajima K, Sasase T, Kimura S, Tong B, et al. Gender differences in metabolic disorders and related diseases in spontaneously diabetic Torii-Lepr(fa) rats. Journal of diabetes research. 2014:2014:841957.

\section{Submit your next manuscript to BioMed Central and we will help you at every step:}

- We accept pre-submission inquiries

- Our selector tool helps you to find the most relevant journal

- We provide round the clock customer support

- Convenient online submission

- Thorough peer review

- Inclusion in PubMed and all major indexing services

- Maximum visibility for your research

Submit your manuscript at www.biomedcentral.com/submit

C) Biomed Central 